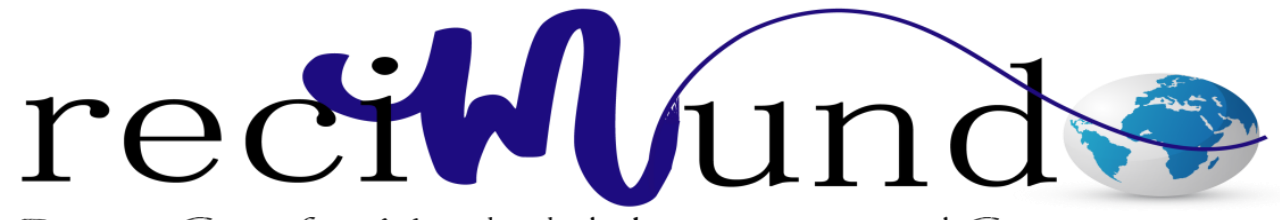

Revista Científica Mundo de la Investigación y el Conocimiento

Winner Wilson Junco Avellan a ; Danny Xavier Junco Ramírez ${ }^{\text {b }}$; Luis Gerardo Santillán López ${ }^{\mathrm{c}}$

Saber hablar en Público

Revista Científica Mundo de la Investigación y el Conocimiento. Vol. 1 núm., 5, diciembre, 2017, pp. 85-106

DOI: $10.26820 /$ recimundo/1.5.2017.85-106

Editorial Saberes del Conocimiento

a. Universidad de Guayaquil.

b. Universidad de Guayaquil.

c. Universidad de Guayaquil. 


\section{Saber hablar en Público}

Vol. 1, núm. 5., (2017)

Winner Wilson Junco Avellan; Danny Xavier Junco Ramírez; Luis Gerardo Santillán López

\section{RESUMEN}

La naturaleza del ser humano nos exige, como individuos, a trabajar internamente en ser personas sociales, nos invita cada día a aprendemos a comunicar, inclusive no solo entre personas sino con el mundo que nos rodea. Es por ello que en la rama de la comunicación vamos observando mecanismo de comunicación con otros seres vivos como animales y plantas. Aprender a comunicarnos nos llama a ser cada día personas empáticas, a desarrollar y trabajar sensibilidades que solo el hombre puede tener en función de las capacidades a desarrollar. De tal manera, el propósito de estas frases, es poner a las personas, a la par de las exigencias de una sociedad cada vez más dinámica o extrovertida, para aquellos que necesitan eliminar el temor, la ansiedad de poderse comunicar con mucho aplomo, tener seguridad de sí mismo. Y desde allí cuidar el mensaje que se quiere dar a través de nuestra comunicación. Saber dirigirnos a un público demanda del comunicador características psicológicas mínimas para que la emisión del mensaje sea efectiva y brindarle a receptor una imagen cómoda para que el mensaje pueda ser escuchado, entendiendo que existe una gran diferencia entre oír un mensaje y escucharlo. El presente trabajo no es más que una recopilación de conceptos y reflexiones del autor, que a través de la investigación bibliográfica enfocada en la epistemología puesto que incluye la experiencia y validación del propio autor, para que el lector vaya obteniendo herramientas básicas que le permitan propiciar un escenario ameno para hablar en público desde su perspectiva de comunicador. Este aporte nace de la observación y entendimiento que saber hablar en público desencadena una cantidad de beneficios para todas las personas que trabajan en corporaciones, profesores universitarios y estudiantes transformadores de cambios personal, laboral y social.

Palabras clave: Autoestima; hablar; comunicar; escuchar; público. 


\begin{abstract}
The nature of the human being requires us, as individuals, to work internally in being social people, invites us every day to learn to communicate, including not only among people but with the world around us. That is why in the field of communication we are observing communication mechanism with other living beings such as animals and plants. Learning to communicate calls us to be empathic people every day, to develop and work sensitivities that only man can have depending on the capacities to be developed. In this way, the purpose of these phrases is to put people, along with the demands of an increasingly dynamic or extroverted society, for those who need to eliminate fear, the anxiety of being able to communicate with a lot of aplomb, having self-confidence And from there take care of the message that you want to give through our communication. Knowing how to address a public demand of the communicator minimum psychological characteristics so that the message is effective and provide the receiver with a comfortable image so that the message can be heard, understanding that there is a great difference between hearing a message and listening to it. The present work is not more than a compilation of concepts and reflections of the author, that through the bibliographical research focused on the epistemology since it includes the experience and validation of the author, so that the reader will obtain basic tools that allow him to propitiate an enjoyable setting to speak in public from his perspective as a communicator. This contribution is born of the observation and understanding that knowing how to speak in public unleashes a number of benefits for all people working in corporations, university professors and transforming students of personal, labor and social changes.
\end{abstract}

Keywords: Self-esteem; speaking; communicating; listening; public. 


\section{Saber hablar en Público}

Vol. 1, núm. 5., (2017)

Winner Wilson Junco Avellan; Danny Xavier Junco Ramírez; Luis Gerardo Santillán López

\section{Introducción.}

En un mundo cambiante en el que los requerimientos de la sociedad, nos invita a reflexionar sobre la necesidad de formar futuros ciudadanos que se integren a un entorno que tiende a la globalización y que exigen, entre otros, muchos valores tales como: honestidad, la responsabilidad, la comunicación, el liderazgo, la innovación y el espíritu de superación personal. Por esta razón, el propósito que se persigue en este trabajo es poner a las personas a la par de las exigencias de las empresas actualizadas y virtuales, mejorando y perfeccionando aquellos aspectos de las personas como: la seguridad, el temor, la ansiedad, la habilidad de comunicación, para ser un buen oyente, la habilidad para incentivar y sobre todo liberar adecuadamente así mismo, que sean unas personas asertivas (facilidad de comunicación, con ala autoestima y autoconfianza, justa, cortes, respetuosa, etc.).

El objetivo principal es que con estas herramientas, se beneficien todas las personas que trabajen en organizaciones y estudiantes universitarios que estudiantes universitarios, aspirantes a administradores, individuos con habilidades administrativas pero interesados en ser aún más eficaces, otros profesionales deseosos de conocer mejor la administración en la que trabajan.

Las personas van a identificar su temperamento, la manera como se desarrollan, conocerán su personalidad en el aspecto si son introvertidos o extrovertidos, con una personalidad normal o anormal, identificarán sus conductas, frustraciones, complejos, perjuicios, y se aliviarán con unas reflexiones, para que asimilen y desarrollen su yo personal, lo cual les va a permitir elevar su autoestima y les ayudará a incrementar su autoconfianza. 
Se han desarrollado temas como la asertividad, donde aprenderán a ser hábil para expresarse, reclamar sobre sus derechos en forma delicada, sutil y positivamente. Aprenderán a ser un buen oyente y empático.

\section{Materiales y métodos.}

En la producción de cualquier conocimiento científico, la herramienta fundamental es el método científico (MC). Luego, antes de concluir en el "nuevo conocimiento" deviene de un "Plan", dado que: Orienta lo que tiene que hacerse: es una guía y obliga a pensar en cada aspecto del estudio; el sólo hecho de escribirlo descubre detalles inconscientemente omitidos, ofrece alternativas de solución: permite que otras personas identifiquen problemas y sugieran soluciones., provee una mejor organización (administración y dirección): facilita el control y evaluación del estudio, tanto por el autor como por otras personas, optimiza la asignación de recursos: ahorra tiempo, reduce la probabilidad de errores costosos, define objetivos coherentes y consistentes, brinda los medios de acción adecuados, evita improvisaciones y decisiones espontáneas, y prevee cambios y modificaciones (Rojas C., 2002)

Al iniciarse la ejecución del proyecto, estará prácticamente agotada la búsqueda de información bibliográfica. Esto debe ser obvio, puesto que no debe ejecutarse un estudio sin antes haber agotado la información teórica respectiva, que es la materia básica a lo largo de la formulación del proyecto (Rojas C., 2002). Los artículos originales de investigación son el plato fuerte de toda revista científica. La publicación de estos artículos es el principal mecanismo utilizado por los investigadores para dar a conocer los resultados de sus estudios. No se llaman originales porque estén tratando sobre temas nunca antes estudiados, sino porque en sí mismos 


\section{Saber hablar en Público}

Vol. 1, núm. 5., (2017)

Winner Wilson Junco Avellan; Danny Xavier Junco Ramírez; Luis Gerardo Santillán López

son una obra científica procedente del razonamiento lógico de sus autores y aportan nuevos datos, abordan vacíos en el conocimiento residuales, exponen aspectos previamente no considerados, analizan elementos complementarios o hacen mayores profundizaciones $\mathrm{y}$ ampliaciones a investigaciones previas. Esto tiene sentido porque en ciencia solo existe una "provisionalidad" del conocimiento y la "reproducibilidad" es algo que caracteriza a la investigación científica (Rojas C., 2002)

Es por ello que, pretendemos ofrecer al lector un cumulo de información para potenciar el autoconocimiento y el autocontrol, para que obtenga las herramientas para manejarse en publico, sobre todo para potenciar la capacidad de escuchar, comunicar y dirigir a un grupo, necesidad imperiosa para las características del mundo corporativo en el que nos desenvolvemos.

\section{Resultados.}

Al observar al ser hmano en sociedad entendemos que existe una caracteriastica evidente de su poryección al mundo, psicológicamente se identifica con el concepto de autoestima, pues a ello se le atribuye al amor propio que puede irradiar una persona. El autoestima quien justifica la postura y la imagen de un hombre en sociedad.

\section{Autoestima}

Los científicos del desarrollo humano, como Car Rogers, Perets Elkins, Mauslow y otros, afirman que la autoestima es fundamental para que el sujeto alcance la autorrealización en la salud física, mental, productiva y creativa. (Estrada, 2015) 
Igualmente, una variedad de autores han expresado que la autoestima es el producto de la experiencia. Hay una corriente generalizada que juzga a la sociedad de acuerdo a nuestro comportamiento.

Es el marco de referencia de su amor a su "yo" personal, y gozar del respeto y dignidad de otros.

\section{Autoimagen Negativa.}

Está compuesta por una serie de situaciones, el temor los limita evitando que se arriesguen en las búsquedas de nuevas soluciones para los problemas, dando paso a un comportamiento agresivo, se oculta tras un muro de desconfianza, hundiéndose en la soledad y el aislamiento, hay un sentido de frustración, enojo y depresión, es rígido en sus valores e inconsciente al cambio, no aprende, se estanca, se deja llevar por los instintos, su control está en mano de los demás.

La Autoestima Negativa, se puede cambiar tomando en cuenta las siguientes estrategias:

\section{Ampliando lo bueno que hay de un sujeto.}

Hay que concentrarse en lo bueno y aprovechar todo lo mejor posible, desechando lo que no sirve.

\section{Identificar y Castigar los Auto comentarios Negativos.}




\section{Saber hablar en Público}

Vol. 1, núm. 5., (2017)

Winner Wilson Junco Avellan; Danny Xavier Junco Ramírez; Luis Gerardo Santillán López

Cuando el sujeto empiece a hablar sobre su incompetencia o a recordar algún aspecto negativo, se obligará a identificar como área de oportunidad, para luego transformarlo en fortaleza.

\section{Es Recomendable Revisar la Autoimagen social.}

Al identificar la situación que es la causa del comportamiento inadecuado, es necesario que se le reste poder a esas malas influencias, con el propósito de tomar control en sí mismo, y dirigir su vida donde cree conveniente, desarrollando habilidades que haga posible aquello.

\section{Miedo a Situaciones Conflictivas.}

Muchas personas se angustian y se quejan, al sentir que son muy emocionales o que no pueden controlar sus sentimientos en situaciones sociales estresantes.

Para ser una persona capaz de eliminar este virus, es sugerible aprender a controlar el estrés, y a manejar los posibles conflictos interpersonales.

Hay que tener en cuenta que las causas que generan esta incapacidad de controlar emociones, son tan diversas, de tal manera que pueden promover una autoestima negativa desencadenando comportamientos y actitudes que obstaculizan su forma de vida, por ello, es importante identificar cuáles son esas causas, para luego contrarrestarlas de la siguiente forma:

Se presenta el diagrama de Bowen y Bowen (1980) para mayor explicación: 


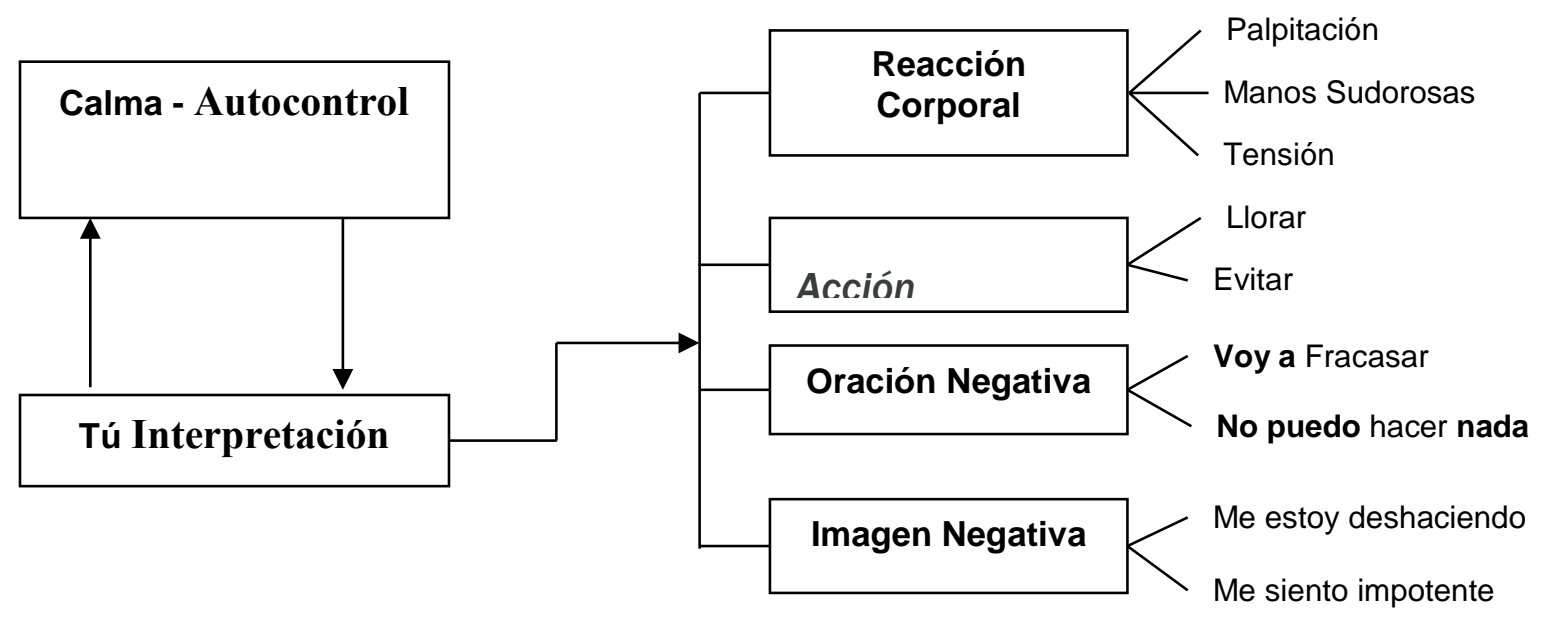

Siempre, todo ser humano tiene capacidad de auto controlarse, sin embargo manejar las capacidades que nuestra mente tiene para controlar cada función del cuerpo. El concepto de estrés es cada vez más común de escuchar entre la cotidianidad social. Es por ello podemos encontrar en mecanismos de manejo del estrés una manera importante de aportar al tema de estudio.

\section{La Relajación para el Manejo del Estrés.}

La forma más idónea para controlar las emociones, disminuir las tensiones, y tener aplomo para hablar con efectividad.

\section{La Tensión Muscular}

La parte física se puede controlar a través de ejercicios de relajamiento como estos:

Mover la Cabeza 5 veces a la derecha y 5 veces a la izquierda, paralelamente, en cada movimiento de la cabeza respirar despacio pero muy profundamente, con los ojos cerrados y relajadamente. Poner la mente en cero. 


\section{Saber hablar en Público}

Vol. 1, núm. 5., (2017)

Winner Wilson Junco Avellan; Danny Xavier Junco Ramírez; Luis Gerardo Santillán López

También se puede hacer ejercicios generales por 30 minutos.

\section{Desensibilización es otra forma de Reducir y Controlar el Temor.}

Obsérvese a través de la imaginación actuando con mucho entusiasmo y éxito, en situaciones posteriores. Cuando le toque estar es ese sitio, ya va con más confianza, porque usted ya estuvo allí en su imaginación, y fue espectacular.

\section{Utilización de Diversas Estrategias.}

Se tendrá la ocasión de disminuir las tensiones y de poder aprender a controlar el estrés en general, si realiza las siguientes acciones:

1. Planificar el tema a tratar

2. Preparar e investigar el temas más de lo normal

3. Practicar el tema en su casa, frente de un espejo.

4. Conversar sobre el tema, con personas que son una autoridad en el mismo.

5. Llegar al sitio con anticipación y comienza a familiarizarte en él.

6. Ponerse de pie, frente al grupo y viéndole la cara a todos.

7. Utilizar una vestimenta elegante, y si es nueva mucho mejor.

8. Aprovechar la Experiencia Ajena.

9. $\quad$ Predisponer su mente para el éxito. 
10. Actuar Resuelto.

11. Ilustrar su charla con ejemplos.

\section{Reflexiones}

Siga estas sugerencias, le ayudará a vencer sus temores de hablar, desarrollará valor y seguridad en sí mismo.

1. Cualquier cosa que pueda hacerle soñar, empiece ya. La audacia es genialidad, poder y magia es sí mismo.

2. Es importante reconocer sus propias limitaciones y debilidades. Siéntase orgulloso de sus capacidades y habilidades. Esto le ayudará a no acercarse a las frustraciones.

3. Retomando una frase de Schuller.

Dale a un hombre una Autoimagen pobre y acabará siendo un siervo.

De esta manera, comienza a pensar cómo una persona de valor y segura de sí misma, porque tal como usted piensa, así será.

4. Arroje al fuego hasta el último pensamiento negativo de su vida.

5. El miedo es hijo de la ignorancia y de la inseguridad.

6. Es bueno mantener la idea de que la frustración es solamente un ligero obstáculo e inconveniente, a la que con seguridad la superaremos con mucha tolerancia. 


\section{Saber hablar en Público}

Vol. 1, núm. 5., (2017)

Winner Wilson Junco Avellan; Danny Xavier Junco Ramírez; Luis Gerardo Santillán López

7. Tener valor, es cosa que no depende de lo que está ocurriendo a su alrededor, depende de lo que está ocurriendo dentro de usted mismo. Sólo sus pensamientos pueden darle valor, y sólo sus pensamientos pueden darle temor.

8. Cuando tenga que hablar, y está con miedo, siga adelante a pesar de su miedo, y su miedo comenzará a desvanecer. Dios favorece a los audaces y fuertes de corazón.

9. Trate de hablar en cada oportunidad que tenga, practique con sus profesores, amigos, padres. La constancia permite ir perdiendo el miedo y llenarse de valor.

10. ¿Sabe cuál es la superación de la inferioridad?

Teniendo su autoestima significativamente bien. Donde despierte en ella un interés de aprender. Es decir, si aprende, la inferioridad la reduce a la mínima expresión sin darse cuenta.

11. La importancia de recopilar más información en general, le llenará de sabiduría. Aplique constantemente estos conocimientos a su propia autoconciencia y al desarrollo de la confianza en sí mismo.

12. Después que usted, haya navegado es su enriquecida experiencia, y salido a flote, será un ganador. Recuerde: "El éxito viene en oleadas"

\section{"Escuchar. Técnicas del Saber Hablar"}

La asertividad como una herramienta de comunicación entre las personas, es el respeto por su integridad, dignidad personal, y a sus deberes y derechos inherentes, tales como la verdad y la libertad. 
La comunicación pasiva, traerá beneficio en el desarrollo individual, es entonces cuando necesitamos encontrar un tipo específico de conducta que mejore las relaciones patronalesempleados, dentro de una institución comercial, educativa y como cualquier otra,

Esta es la conducta asertiva, aquella implica necesariamente la habilidad de saber escuchar activamente, la cual nos permitirá emitir la mejor respuesta a las demandas de las otras personas.

\section{$\underline{\text { Escuchar }}$}

Significa poner atención y comprender las ideas, opiniones y sentimientos que otras personas transmiten.

El oyente debe estar en condiciones de estar atento, de manera que pueda ir entendiendo y asimilando a medida que las palabras broten del emisor. Esto quiere decir, que el emisor no puede perder nunca el contacto con el oyente. Generalmente, debe existir doble vía porque corre el riego de que cese la atención, y el mensaje no llegue.

Hay que buscar la manera que el oyente no se fatigue por el esfuerzo que tenga que realizar para ir receptando lo que dicen, y al final deja de percibir con claridad.

Se podría señalar que todo individuo, cualquiera que sea su condición social, estará a la expectativa de significar algo para alguien, y saberse aceptado y escuchado por los demás. Recordemos que, así como le gusta que lo escuchen y atiendan cuando le hablan, a otras personas les pasa similar y se debe ser recíproco. En muchas ocasiones, es algo psicológico. 


\section{Saber hablar en Público}

Vol. 1, núm. 5., (2017)

Winner Wilson Junco Avellan; Danny Xavier Junco Ramírez; Luis Gerardo Santillán López

A menudo las personas, no escuchan todo lo que piensan haber oído. La gran mayoría de nosotros no somos personas con gran habilidad para escuchar.

Algunos escritores, con relación al tema coinciden, que aun cuando una persona piensa que escuchó atentamente, sólo captó el $50 \%$ de lo que se oyó. Después de dos días, sólo podrá recordar el $25 \%$ del mensaje original.

Actualmente, es notorio que los altos ejecutivos tienen que cubrir muchos desafíos y uno de los puntos claves, es precisamente la comunicación, en que debe ser un excelente oyente, de esta manera, su tratamiento con sus colaboradores será de plena satisfacción, porque podría entenderlos y solucionar problemas futuros.

\section{Objetivo de Escuchar}

Cuando realmente se escucha, es para cumplir con cierto fin personal, ya sean estos:

\section{a. Escuchar por Placer}

- Sintetizando, que escuchar por placer se da ante un personaje donde exista mucha admiración.

- Recuerde, que un ligero acento, es una ventaja. Frecuentemente le da una distinción a un hombre, y un encanto a una mujer.

\section{b. Escuchar por Entender}

- Podríamos identificar sus principales ideas, y razonar paulatinamente cada una de ellas.

- Relacionar su mensaje con un conocimiento previo, y así asimilar mejor. 
Winner Wilson Junco Avellan; Danny Xavier Junco Ramírez; Luis Gerardo Santillán López

- En muchas ocasiones, entender el silencio y las emociones del emisor.

- Resaltar el orden de sus ideas.

\section{c. Escuchar para Evaluar}

En repetidas ocasiones, nos toca el papel de escuchar, y diagnosticar sus conocimientos, su forma de pararse, de hablar, observar los gestos del sujeto, donde se tiene que hacer un juicio, comentario y valorar al respecto.

\section{d. Escuchar para Recordar}

Usualmente se debe poner en práctica todo lo que se escucha y se observa, para luego, maximizar lo que más se recuerde, y verificar posteriormente en que aspecto de la vida personal, profesional y laboral han mejorado.

Es notorio ver en las personas sus cambios, después de aplicar todo lo recordado y aprendido a lo largo de su vida.

\section{Usar la Empatía al Escuchar}

A menudo se escucha a diferentes personas decir: No comprendí lo que quiso decir aquella persona. Otras, no me entienden. No me puedo comunicar.

Normalmente encontramos en la mayoría de las personas, la incapacidad para escuchar. Una de las partes fundamentales para entender es Tratar de comprender los silencios y las emociones de los sujetos. Podría resultar algo difícil e incomprensible, pero se debe intentar hacerlo. 


\section{Saber hablar en Público}

Vol. 1, núm. 5., (2017)

Winner Wilson Junco Avellan; Danny Xavier Junco Ramírez; Luis Gerardo Santillán López

La empatía se emplea para expresar una identificación emocional. Es decir, ubicarse en los zapatos de la otra persona, cuando desea que se lo comprenda.

Inteligentemente la persona empática, toma los argumentos, detalles emocionales de la otra persona, al realizar esto, ve todas las cosas desde otro punto de vista. Afectivamente siente o experimenta las emociones de la otra. De esta manera, el individuo toma la decisión del caso.

\section{La empatía desde el punto de vista práctico.}

Generalmente, se ve en los Gerentes, Ejecutivos maduros y competitivos, cuando sus colaboradores comienzan a solicitarles algo o tienen problemas de diferentes índoles.

Para resolverles los problemas individuales, tienen que usar la empatía, viendo sus expresiones, sus gestos, sus necesidades, conocer cuando les están diciendo la verdad o mentira.

\section{Escuchar Adecuadamente Mejorará la Habilidad del Sujeto}

Las relaciones interpersonales juegan un papel muy importante en el desarrollo humano, donde le va a permitir evaluar sus habilidades para ser empático, por ello, ponga en práctica estos ejemplos.

Recuerde, el que sabe escuchar, sabe hablar, y disfrutar de la vida.

1. Esté verdaderamente interesado del tema a tratar.

2. Ponga su mente en cero, relájese y disfrute de la charla.

3. Anote las ideas más relevantes, y después medite, y compréndala a su manera. 
4. Utilice su cultura, ponga la atención que merece al interlocutor.

5. Concéntrese en los detalles y ejemplos, que le ayudarán a recordar el tema.

6. Escuche detenidamente las experiencias del sujeto, que de ellas aprenderá mucho.

7. Imagínese cómo se sentiría en el lugar del otro cuando escuche.

8. Aprenda la combinación de su lenguaje con los gestos y movimientos expresados.

9. Resuelva sus problemas, a través de las experiencias vividas de otros.

10. Sea generoso con su entusiasmo al escuchar, y ganará amigos

Comunicación Científica personalizada se realiza mediante dos modalidades: la oral y la textual-gráfica. Aquí es necesario agregar que, el informe escrito, es también otra forma de comunicación científica. Pero nos atañe al tema entender que saber hablar en público repercute en la capacidad que tiene el científico de aportar a la comunidad donde se desenvuelve.

Se conoce como disertación a la exposición oral sobre un tema, y también, como parte de la ciencia maneja una metodología para poderla desarrollar.

\section{La disertación científica o exposición oral}

La mayoría de las disertaciones científicas (DC), en casi todos los certámenes duran 10 minutos, siendo mayor en el simposio (20 minutos) y en el seminario (hasta una hora). de manera que es muy importante organizar la DC en función del tiempo. Entonces: 


\section{Saber hablar en Público}

Vol. 1, núm. 5., (2017)

Winner Wilson Junco Avellan; Danny Xavier Junco Ramírez; Luis Gerardo Santillán López

\section{¿Qué comunicar?: El tema.}

La DC tiene como referente al "esquema lógico" del método científico, pero, con una presentación: ágil, clara y eficaz del "hallazgo científico y sus implicancias". Luego, el siguiente listado de preguntas extraerá el mensaje que se debe comunicar.

1) ¿Por qué se hizo el estudio?: El problema y Objetivo (o hipótesis). ¡Brevemente!.

2) ¿Cómo se hizo?: El procedimiento experimental. ¡Sin detallar!

3) ¿Qué se encontró?: Los resultados. ¡Brevemente!, en 1, 2 o 3 cuadros y/o figuras.

4) ¿Qué significancia tiene?: ¡Expláyese!, especulando sobre los resultados, las conclusiones y sus implicancias.

5) ¡Concluya!: Agradeciendo a la audiencia.

\section{¿Cómo hablar?: Actitud del disertante}

Mirar a la audiencia, y no al: techo, pizarra, paredes o apuntes. Es un gesto de respeto al público y ayuda a conseguir simpatía. ¡Nunca hable de espaldas al público!.

Adecuar el tono de voz a la velocidad de hablar. Es aconsejable \pm 100 palabras por minuto, claramente pronunciadas. Entre los auditores hay normalmente una proporción con sordera incipiente, y la ayuda del amplificador no será suficiente sino se habla "clara y pausadamente".

Cuidar la pronunciación para enfatizar sílabas, acentos, y especialmente "palabras clave" y “técnicas". Es bueno además escribirlas en la pizarra. 
Evitar gestos que distraigan a la audiencia, ejs: manía de sacar y meter las manos del bolsillo, juguetear con el lapicero, puntero, etc. La disponibilidad de "fichas o tarjetas de ayuda" es un buen “disimulador de manías". (Rojas C., 2002)

\section{Conclusiones}

Hablar en público es una de las experiencias más fabulosas que esperan al ser humano. La conexión con una audiencia es muy gratificante. Pero esperamos con miedo el momento de presentarnos ante ella., hablar ante un grupo es lo que más temen los conciudadanos de EE.UU. Es un pavor que atenaza a demasiadas personas (Acosta Vera, 2013)

Se puede hablar en público en ocasiones muy diversas: En lo profesional incluye: • Conferencias. Presentaciones.

- Entrevistas en periódicos.

- Apariciones en TV.

- Ruedas de prensa.

- Convenciones. Comités. Asambleas.

- Demostraciones. Cenas de empresa. Inauguraciones.

Es fácil dar el salto. Poder hacerlo de modo elegante y persuasivo, con convicción, es vital para cualquier persona. De ello depende muchas veces el reconocimiento de sus capacidades y su progresión como persona. (Acosta Vera, 2013) 


\section{Saber hablar en Público}

Vol. 1, núm. 5., (2017)

Winner Wilson Junco Avellan; Danny Xavier Junco Ramírez; Luis Gerardo Santillán López

Se ha dicho que el orador nace, esto es solo una verdad a medias, algunos pueden gozar del don per la perfeccion sugiere un camino de perfeccion que pueden recorrer los que han de servirse de ella. (Carbonell)

A mayor miedo a la evaluación negativa mayores son las alternativas de implicación, mayores son las inversiones personales y mayores son las coacciones sociales; a mayor ansiedad y evitación social ante extraños, menor es la diversión, mayores son las alternativas de implicación y las coacciones sociales y menor es la implicación. (Prieto, 2016)

En cuanto a la ansiedad general, ésta cuando es mayor reduce la diversión, aumentando las coacciones sociales; a mayor motivación orientada a alcanzar el éxito mayor es la diversión. (Prieto, 2016)

A mayor competitividad mayor es la diversión; a mayor implicación en los resultados mayores son las coacciones sociales. Por otra parte, a mayor implicación en la tarea mayor es el compromiso, la diversión y la implicación, menores son las coacciones sociales y las alternativas de implicación y menores son las inversiones personales; por último, a mayor grado de diversión mayor es el compromiso y mayor es la implicación (Prieto, 2016)

El aprender y desarrollar estas habilidades en uno mismo es fundamental para conseguir unas óptimas relaciones con los otros, ya sean de carácter social, familiar, laboral, etc. Por otra parte, somos más sensibles a las necesidades de los demás y tenemos mejores instrumentos para "modelar" su conducta. Modelar, como sabemos, es guiar la conducta y el pensamiento del otro con el comportamiento y con una actitud personal al cambio, lo cual significa que podemos facilitar de esta manera el cambio también en los otros. (Grimaldi Herrera, 2016) 
Al ser un conjunto de comportamientos capaces de aprenderse, hemos de darnos cuenta, en primer lugar, de qué habilidades tenemos y somos capaces de dominar y de qué otras carecemos y hemos de trabajar más. (Grimaldi Herrera, 2016)

Es necesario comprender es que para cambiar la cultura necesitamos ampliar nuestra conciencia para observar nuestras propias cegueras cognitivas, lo cual sólo es posible mediante la reflexión individual y colectiva. (Gómez, 2016)

De lo que se entiende por cultura, nos podemos dar cuenta que trabajar en ella, significa trabajar con el mundo interior, con el lado subjetivo, e intersubjetivo de la realidad (modelos mentales individuales y colectivos), donde se encuentran los valores, las creencias, las emociones, los motivos y la espiritualidad de la organizaciones y de las personas que la conforman. Por consiguiente, trabajar con el mundo interno requiere pensar en otras herramientas distintas a las que usamos para trabajar con el "mundo exterior", con el mundo objetivo de los comportamientos y sistemas socio-ambientales. Esto significa que la organización debe desarrollar otras competencias, que no son técnicas, sino emocionales y conversacionales. (Gómez, 2016)

\section{Bibliografía.}

Acosta Vera, J. M. (2013). Hablar en público. Madrid: ESIC Editorial.

Carbonell, R. G. (s.f.). Todos pueden hablar bien en público. 2017: Edaf.

Estrada, M. R. (2015). Autoestima: clave del éxito personal. El Manual Moderno.

Gómez, F. M. (2016). Influencia de los líderes en la cultura de los sistemas de gestión. Revista Interamericana de Psicología Ocupacional, 29(1), 74-82., 1(29), 74-82.

Grimaldi Herrera, C. (2016). Habilidades Sociales. Contribuciones a las Ciencias. 


\section{Saber hablar en Público}

Vol. 1, núm. 5., (2017)

Winner Wilson Junco Avellan; Danny Xavier Junco Ramírez; Luis Gerardo Santillán López

Prieto, J. M. (2016). Relación entre competitividad, ansiedad social y compromiso con variables deportivas y académicas en futbolistas jóvenes. Revista iberoamericana de psicología del ejercicio y el deporte, 11(2).

Rojas C., M. (2002). Manual de Investigación y redacción científica. Lima: Book xxpress. 